Running Head: Psychological Well-Being in a Turkish-Canadian Sample

Psychological Well-Being in a Turkish-Canadian Sample

\author{
Ayse K. Uskul, PhD* \\ University of Michigan \\ Ann Arbor, MI
}

\author{
Esther Greenglass, $\mathrm{PhD}$ \\ York University \\ Toronto, Canada
}

* Correspondence concerning this article should be addressed to Ayse K. Uskul, Research

Centre for Group Dynamics, Institute for Social Research, 426 Thompson Street, Ann Arbor, MI, 48104, USA. E-mail: auskul@umich.edu 


\begin{abstract}
The study examined predictors of psychological well-being in a sample of 181 Turkish immigrants living in Toronto, Canada. Depression and life satisfaction were employed as indicators of psychological well-being. A model was put forth in which proactive coping and optimism were hypothesized to predict negatively to depression and positively to life satisfaction. Proactive coping consists of efforts to build up general resources that facilitate the achievement of challenging goals and promotes personal growth and was expected to contribute to the prediction of psychological well-being over and above the effects of optimism. Hierarchical regression analyses were conducted with life satisfaction and depression as criteria and demographics, optimism, and proactive coping as predictors. In general, the results supported the hypotheses; the model fit better when the criterion was depression than when life satisfaction was the criterion.
\end{abstract}

Key Words: depression, life satisfaction, optimism, proactive coping Abstract word count: 134 words Main body text word count: 3232 words 


\section{Psychological Well-being in a Turkish-Canadian Sample}

Traditionally, psychological research has focused on negative states, their determinants and consequences. Studies on depression, separation, alienation, and similar topics focus on people's suffering and its deleterious effects on their psychological and physical states. Until relatively recently, little study has been conducted on subjective moods or feelings of well-being and their determinants. Subjective feelings of well-being, one of the hallmarks of health, are characterized not only by low levels of depression but also higher levels of life satisfaction. These variables, as indices of psychological well-being, have been extensively studied in previous research (e.g. Chang, 1998; Crocker, Luhtanen, Baline \& Broadnax, 1994; Shehan, 1984). Numerous studies showed that depression, for example, relates negatively to positive psychological variables such as self-esteem and optimism, and positively to negative psychological variables such as hopelessness. Life satisfaction, on the other hand was found to relate positively to positive psychological variables and negatively to negative psychological variables. This study focuses on several factors that relate to psychological well-being.

It is commonly thought that coping is a major predictor of psychological well-being. Coping refers to a complex process of behavioral and cognitive efforts to manage the internal and external demands of a stressful situation (Lazarus, 1993; Lazarus \& Folkman, 1984) and involves personality characteristics, personal relationships, and situational parameters (Pierce, Sarason, \& Sarason, 1996). Discussions of coping often take into account what people do and feel following the occurrence of a stressful event. Coping may take various forms depending on when it occurs and the associated demands and resources. Schwarzer (1999a, 2000) distinguishes between reactive and proactive coping: Reactive coping is defined as an effort to deal with a stressful encounter that has already happened. Since the 
stressful events have already taken place, coping efforts are directed here to either compensating for a loss or alleviating harm. In general, this is the type of coping that has been assessed in much of the research on coping to date. Proactive coping consists of efforts to build up general resources that facilitate the achievement of challenging goals and promote personal growth.

The concept of proactive coping, with its positive focus, is in line with recent developments in psychology that urge psychologists to adopt perspectives that incorporate human potential, striving, motives and capacities (Seligman, 1990; Sheldon \& King, 2001; Taylor \& Aspinwall, 1996). The Proactive Coping Inventory (PCI) (Greenglass, Schwarzer \& Taubert, 1999) was constructed in order to assess the various aspects of coping proactively and consists of six subscales that assess these various dimensions. For purposes of this study, we will focus only on one of the PCI subscales, namely the proactive coping subscale, a 14item scale that combines autonomous goal setting with self-regulatory goal attainment cognitions and behavior. The scale was shown to have has high internal consistency and good item-total correlations and acceptable skewness. A principal component analysis confirmed its factorial validity and homogeneity (Greenglass, Schwarzer, \& Taubert, 1999).

Previous research has shown that scores on the proactive coping subscale are positively correlated with internal control and active coping (Greenglass, Schwarzer, \& Taubert, 1999), with self-efficacy in a sample of Polish-Canadian adults and Canadian students (Greenglass, Schwarzer, \& Taubert, 1999), with life satisfaction (Greenglass, 2002a), professional efficacy and perceptions of fair treatment at work (Greenglass, in press). Proactive coping subscale negatively correlates with self-blame, denial, and job burnout (Greenglass, 2002a; Greenglass, Stokes, \& Fiksenbaum, in press) and with depression, in a sample of elderly adults (Fiksenbaum, Greenglass \& Eaton, 2001), in Polish-Canadian adults 
and Polish students (Greenglass, 2002; Pasikowski, Sek, Greenglass, \& Taubert, 2002). Thus, proactive coping was found to be negatively correlated with psychological variables such as depression, which has been characterized by personal deficiency, self-blame and pessimism (Beck, 1967) as well as avoidance and self-defeating ways (Burns, 1999), and to be positively related to positive psychological variables, such as life satisfaction, that imply a general positive feelings about life.

\section{Proactive coping and optimism}

Optimism, defined as generalized positive outcome expectancies, represents a relatively stable individual difference variable that promotes psychological and physical well-being. Recent empirical studies showed that optimists are psychologically better adjusted and are physically healthier than their more pessimistic counterparts (for a review, see Scheier \& Carver, 1992 and Scheier, Carver, \& Bridges, 2001). According to the model presented by Scheier and Carver (1985), optimists are better adjusted than pessimists due to their tendency to change conditions related to a stressful situation rather than ignore or withdraw from it. This kind of coping was believed to increase the likelihood that conditions related to the stressful situation will be effectively addressed or resolved (e.g., Bandura 2000; Chang, 1998; Rim, 1990; Scheier, Carver, \& Bridges, 1994). Numerous studies have pointed to the importance of optimism as an important regulator in how people cope with stressful events. Optimism can be considered to be a part of a proactive coping style, in that a proactive coper evaluates difficulties in more positive terms and views them as challenges rather than threats. Therefore, proactive coping and optimism are expected to be positively correlated. At the same time, proactive coping involves more than being an optimist in that it equips the individual with a wider set of skills for successful management of life goals 
including the management of stressors. Therefore, it is expected that proactive coping should be related to psychological well-being over and above the effects of optimism.

Psychological well-being and demographic variables

In the present study, the role of optimism and proactive coping is examined as predictors of psychological well-being in a sample of Turkish immigrants. Depression and life satisfaction are employed as indicators of psychological well-being. While there is considerable literature on adjustment of immigrant groups to new cultures, little is known about the psychological ways in which adjustment takes place. The study of coping in an immigrant sample is most appropriate given that they have to deal with many stressors associated with their immigrant status. Not only do they have to find a new job, but also they need to adjust to the norms, mores and language of the host country (e.g., Berry, 1997; Berry \& Sam, 1997). In addition, applying the concept of proactive coping to an immigrant sample will contribute to the generalization of earlier findings related to the proactive subscale of the PCI.

The sample in the present study consisted of Turkish immigrants living in Toronto. While the number of Turkish immigrants has been increasing rapidly worldwide, their numbers have particularly increased in Canada from approximately 5000 in 1986 to over 18,000 ten years later (Statistics Canada, 2001). Previous research with Turkish immigrants living in Canada has shown that marital status, education, and socio-economic status are significantly related to psychological well-being. For example, Aycan and Berry (1996) have shown that Turkish immigrants with higher occupational status, which requires higher levels of education, reported better psychological health. Similarly, Ataca and Berry (2002) have shown that Turkish immigrants in their sample displayed different acculturation experiences 
and level of life satisfaction as a function of their socioeconomic status and that marital variables displayed close relations with psychological adaptation in this population.

In line with previous research on Turkish immigrants in Canada and general wellbeing research, in the current study, we expected the following demographic variables to be related to psychological well-being: marital status, gender, and education. Research has shown that marriage can be a source of emotional and social support for couples and that married people enjoy better psychological health (e.g. Kim \& McKenry, 2002; Lamb, Lee, \& DeMarris, 2003; Ross, Mirowsky, \& Goldsteen, 1990). It is believed that marriage can be an important source of well-being in an immigration context as it might be one of the few sources of social support that immigrants have available to them (e.g., Baltas \& Steptoe, 2000). Research on gender differences in well-being suggest that women, compared to men, are over represented among the poor, are more likely to experience inequities in the work force than men and experience more work-family conflict (e.g., Greenglass, 2000). Since these factors are associated with decreased psychological well-being, women should experience lower levels of psychological well-being than men, as shown in higher levels of depression and lower levels of life satisfaction. Additionally, education was expected to be related to greater well-being in this population since it would equip immigrants with the necessary resources to be used with the demands of their new lives (Ataca \& Berry, 2002; Aycan \& Berry, 1996).

\section{Hypotheses}

The present study was designed to examine predictors of psychological well-being in Turkish Canadian immigrants using depression and life satisfaction as indicators of wellbeing. The role of proactive coping and optimism as predictors of psychological well-being was examined using hierarchical multiple regression, controlling for the effects of 
demographic variables. In this study we hypothesized that proactive coping and optimism would positively predict life satisfaction and negatively predict depression. Additionally, a positive relationship between proactive coping and optimism was expected, as well as an additive predictive value of proactive coping to psychological well-being, over and above the effects of optimism.

\section{Method}

\section{Participants}

The sample consisted of 181 Turkish immigrants (106 men and 75 women) living in Canada. The mean age was 32.6 years $(S D=9.66)$, ranging from 19 to 59 years. Thirty-nine percent of the total sample had a graduate degree, $35.7 \%$ were university graduates, $19 \%$ were secondary or community college graduates, and $4.3 \%$ had lower degrees. The majority of the sample $(72.8 \%)$ was comprised of recent immigrants who immigrated or entered Canada with a student visa within the last 10 years. The mean length of stay in Canada was 7.5 years $(S D=8.6)$, ranging from 1 to 33 years. Eighty-eight percent of the participants were born in Turkey, $4.4 \%$ were born in Canada ${ }^{1}$.

\section{Procedure}

Recruitment of participants was accomplished by using a multiple sampling strategy. The three main sources used were: the listserve of a Turkish magazine in Toronto, the community attending two mosques in Toronto, and two Turkish student associations at two universities in Toronto. The aim of the study was explained to potential participants and the anonymous self-report questionnaire was either handed in or sent via e-mail to the volunteering participants. On some occasions, participants filled out the questionnaire in the presence of the researcher, on others, they were asked to mail the questionnaire back to the researcher. In the former case, the questionnaires were handed out to the volunteers either in 
community centers before or after social activities or at other gatherings in the community. The overall response rate based on these abovementioned three sampling methods was $67 \%$. In addition to these methods, sampling through the snowball technique was also used. The overall sample can be characterized as a sample of convenience.

All the measures, except the Beck Depression Scale, were translated into Turkish by the first author, who is a native Turkish speaker. The translation was finalized after the initial translation was discussed and consensus was achieved in 2 focus groups consisting of bilingual Turks. All participants received the questionnaire in Turkish.

\section{Measures}

The questionnaire included sections on demographic/background information, coping, optimism, and psychological well-being, measured by the level of depressive symptoms and life satisfaction.

Demographic/background information. The demographic variables were gender, age, length of stay in Canada, education, marital status, and place of birth.

The Proactive Coping Subscale $(\alpha=.79)$. The Proactive Coping Scale consists of 14 items (Greenglass, Schwarzer, \& Tauber, 1999). For each item, respondents were presented with four alternatives: "not at all true (1)", "barely true (2)", "somewhat true (3)" and “completely true (4)". The instructions for the scale read as follows: "The following statements deal with reactions you may have to various situations. Indicate how true each of these statements is depending on how you feel about the situation". A sample item for this scale is "I like challenges and beating the odds."

Beck Depression Inventory $(\alpha=.87)$. The Beck Depression Inventory (Beck, et al., 1961) was used to assess depression. The Turkish version of the BDI was employed that was standardized in various Turkish samples (Hisli, 1985). For each item in the 21-item 
inventory, respondents were asked to choose from a group of four statements (rated 0 to 3 in depressive symptomatology) the one that best described the way they were feeling during the last month. Higher scores indicate higher levels of depression.

Optimism Scale $\left(\alpha=.55^{2}\right)$. Optimism was measured by the 5-item Revised Life Orientation Test (LOT-R) ${ }^{3}$ (Scheier, Carver \& Bridges, 1994) based on the Life Orientation Test (LOT) developed by Scheier and Carver (1985). A sample item is "In uncertain times, I usually expect the best". Participants were asked to indicate the extent to which they agreed with each of the items on a 5 point scale with the endpoints: $1=$ strongly disagree and $5=$ strongly agree.

Life Satisfaction Scale $(\alpha=.87)$. The level of satisfaction in life was assessed by a 3item Life Satisfaction Scale developed by Bachman, Kahn, Davidson and Johnston (1967). Respondents evaluated their level of satisfaction using a scale from 1 (not at all true) to 7 (always true). The three items in this scale are: "I find a great deal of happiness in life", "I am very satisfied with life", and "I generally feel in good spirits".

\section{Results}

Table 1 presents the intercorrelations of the study variables. Life satisfaction was significantly positively correlated with proactive coping and optimism. Depression was significantly negatively correlated with optimism, proactive coping, life satisfaction, and education. Age correlated significantly positively with optimism.

A hierarchical regression was conducted to examine the predictive power of demographic variables ${ }^{4}$, optimism, and proactive coping for depression. In a three-step hierarchical regression, marital status, gender, education, and length of stay in Canada were entered in step 1 , followed by optimism in step 2, and proactive coping in step 3 . Depression was significantly associated with not being married and correlated significantly negatively 
with education (see Table 2). Optimism had a significant negative contribution to depression above and beyond the demographic variables. Finally, proactive coping contributed significantly negatively to depression above and beyond the contribution of demographic variables and optimism. In summary, being married, high levels of education, having an optimistic attitude towards life, and coping proactively were associated with lower levels of depression.

The same hierarchical regression was repeated for life satisfaction. As reported in Table 3, life satisfaction was marginally significantly associated with being married $(p=$ .073 ) and being female $(p=.066)$. Optimism contributed significantly positively to life satisfaction above and beyond the demographic variables. Proactive coping predicted life satisfaction above and beyond the demographic variables and optimism only at a marginal significance level $(p=.068)$. In summary, being married, being female, having an optimistic attitude towards life, and coping proactively were associated with higher levels of life satisfaction.

\section{Discussion}

In general, the model proposed here that optimism and proactive coping would predict greater psychological well-being, was supported by the data. Proactive coping predicted psychological well-being above and beyond demographic variables and optimism significantly in the case of depression and marginally significantly in the case of life satisfaction. While the model accounted for $30 \%$ of the variance when predicting to depression, the same model accounted for only $18 \%$ of the variance in life satisfaction. It may be that life satisfaction, compared to depression, depends more on one's social roles and the extent to which they prove to be satisfying for the individual. Research findings in the organizational area, for example, indicate that satisfaction with work and family roles are 
significant predictors of life satisfaction as is role conflict between these two spheres (Greenglasss, 2000). The relative importance of social roles compared to optimism and coping as predictors of life satisfaction, could be tested in future research. Also, in an immigration context, psychological resources such as optimism or proactive coping may be more useful in preventing depression and relatively less useful in life satisfaction, where other factors such as occupational and social roles may be more important.

As expected, education significantly predicted depression - higher education was associated with lower depression, results that have been reported elsewhere (e.g. Oliver \& Simmons, 1985; Pahkala, Kesti, Koengaes-Saviaro, Laippala, et al., 1995; Ross \& Van Willigen, 1997; Ying, 1988). With greater education, there may be a greater sense of control that is both domain specific and more general given the greater options in life style, career and time management. Being married was also found to be a significant predictor of psychological well-being. Married participants reported higher levels of life satisfaction and lower levels of depression than their single, divorced or widowed counterparts. These results are in line with the existing literature on the positive relationship between being married and psychological well-being (e.g. Kim \& McKenry, 2002; Lamb et al., 2003). Marriage can be a powerful source of social support, especially in an immigration context where people tend to rely on the support of their nuclear families instead of the social support of the extensive families and large circle of friends that would be more likely to be available in a nonimmigration context (e.g., Baltas \& Steptoe, 2000). Gender related to psychological wellbeing only marginally significantly in the case of life satisfaction. Thus, gender did not appear to be an important predictor of psychological well-being among immigrants to Canada from Turkey. Given the relatively high level of education of this sample, sociocultural factors may be more significant contributors to one's well-being than gender. The 
length of stay in Canada was not associated with either of the psychological well-being variables. It may not be length of stay, per se, that predicts to well being, but rather, the quality of their stay in Canada may be a more important factor. Future research could address this issue by assessing the extent to which participants realized their goals and achievements. The data suggest further that optimism and proactive coping are predictors of psychological well-being, as measured by self reports of depression and life satisfaction, albeit more with regard to depression.

The results reported here provide further evidence of the significant negative relationship between proactive coping and lower depression scores, findings that have been reported in several samples differing in culture and age, including Polish Canadians and Canadian students (Greenglass, 2002a; Greenglass, Schwarzer, \& Taubert, 1999), in Polish students (Pasikowski, Sek, Greenglass, \& Taubert, 2002) and in Canadian elderly (Greenglass, 2002b). Moreover, the present findings demonstrating a negative relationship between proactive coping and depression have been confirmed in yet another cultural group, Turkish Canadian adults living in Canada, using hierarchical regression where demographic variables were controlled for. Thus, it appears that when individuals cope with events using proactive strategies, they are less likely to report feeling depressed with its accompanying feelings of personal deficiency, self-blame and pessimism (Beck, 1967) as well as avoidance and self-defeating ways. This may be due in part to the finding that proactive coping is active and self-initiating, rather than passive, (Greenglass, 2002a). Thus, to the extent that proactive coping is antithetical to depression, individuals who use it to cope with day to day threats, are less likely to experience and report depression.

One of the limitations of this study was that it was cross-sectional, thus precluding inferences of causality among variables. The results of the hierarchical regressions suggested 
that optimism and proactive coping contributed to greater psychological well-being.

However, it cannot be ruled out that greater psychological well-being may also contribute to greater optimism and proactive coping. While theoretical considerations tend to favor the former rather than the latter interpretation, in future research, directionality of variables may be further explored using a longitudinal design.

Another limitation concerns the lack of a measure of acculturative stress that would be most relevant to our sample of immigrants who are likely to face stressors uniquely associated with the acculturation process. The current study also did not include a measure of past, present, or future stress. Examining how proactive coping may interact with different types of stress in its impact on psychological well-being would further contribute to our understanding of the role of proactive coping. Finally, the sample of the current study was comprised of Turkish immigrants living in Toronto. This may limit generalizations of the results. It is believed, however, that the characteristics of the sample are similar to those of Turkish immigrants in the rest of North America (Ahmed, 1993). The dominant presence of highly educated participants in this sample also represents the immigration policy of the Canadian State that emphasizes the selection of candidates for immigration on the basis of their high educational attainment and occupational qualifications (Green \& Green, 1995). Nevertheless, future studies should aim at random sampling using different sources of population records. 


\section{References}

Ahmed, F. (1993). Turks in America: The ottoman Turks' immigrant experience. U.S.A.:

Columbia International.

Ataca B., \& Berry, J. W. (2002). Psychological, sociocultural and marital adaptation of Turkish immigrant couples in Canada. International Journal of Psychology, 37, 1326.

Aycan, Z. \& Berry. J. W. (1996). Impact of employment-related experiences on immigrants' psychological well-being and adaptation to Canada. Canadian Journal of Behavioral Science, 28, 240-251.

Bachman, J., Kahn, R. L., Davidson, T. \& Johnston, L. (1967). Youth in transition Volume 1. Ann Arbor, MI: Institute for Social Research.

Baltas Z. \& Steptoe A. (2000). Migration, culture conflict and psychological well-being among Turkish-British married couples. Ethnicity and Health, 5, 173-180.

Bandura, A. (2000). Cultivate self-efficacy for personal and organizational effectiveness. In E. A. Locke (Ed.), The Blackwell handbook of principles of organizational behavior (pp. 120-136). Blackwell Publishers, Oxford, UK.

Beck, A. T. (1967). Depression: Clinical, experimental, and theoretical aspects. New York: Harper \& Row.

Beck, A. T., Ward, C. H., Mendelson, M., \& Garrison, B. (1961). An inventory for measuring depression. Archives of General Psychiatry, 4, 561-571.

Berry, J. W. (1997). Immigration, acculturation and adaptation. Applied Psychology: An International Review, 46, 5-68. 
Berry, J. W. \& Sam, D. L. (1997). Acculturation and adaptation. In J. W. Berry, M. H.

Segall\&C. Kagitcibasi (Eds.) Handbook of Cross-cultural Psychology, Vol. 3: Social behaviour and Applications, (pp. 291 - 326). Boston: Allyn \& Bacon.

Burns, D. (1999). The feeling good handbook. New York: Penguin.

Chang, E. C. (1998). Does dispositional optimism moderate the relation between perceived stress and psychological well-being?: A preliminary investigation. Personality and Individual Differences, 25, 233-240.

Crocker, J., Luhtanen, R., Baline, B. \& Broadnax, S. (1994). Collective self-esteem and psychological well-being among White, Black, and Asian college students. Personality and Social Psychology Bulletin, 20, 503-513.

Fiksenbaum, L., Greenglass, E. R., \& Eaton, J. (2001, July). Proactive coping, well-being and adjustment in the elderly. Paper presented at the $22^{\text {nd }}$ International STAR conference, Palma de Mallorca.

Green, A. G. \& Green, D. A. (1995). Canadian immigration policy: the effectiveness of the point system and other instruments. Canadian Journal of Economics, 28, 10061041.

Greenglass, E. (2000). Work, family and psychological functioning: conflict or synergy? In P. Dewe, M. Leiter \& T. Cox (Eds.), Coping, health and organizations (pp. 87-108). London: Taylor and Francis.

Greenglass, E. R. (2002a). Proactive coping In E. Frydenberg (Ed.), Beyond Coping: Meeting Goals, Visions and Challenges (pp. 37-62). London: Oxford University Press.

Greenglass, E. R. (2002b). Proactive coping, stress and social support: Psychological implications. Invited Address given at the XXV International Congress of Applied Psychology (IAAP), Singapore. 
Greenglass, E. R. (2005). Proactive coping, resources and burnout: Implications for occupational stress. In A. S. Antoniou \& C. Cooper (Eds.), Research Companion to Organizational Health Psychology (pp. 503-515). London: Edward Elgar.

Greenglass, E. R., Schwarzer, R., \& Taubert, S. (1999). The Proactive Coping Inventory (PCI): A multidimensional research instrument. [On-line]. Available: http://www.psych.yorku.ca/greenglass/pci.html

Greenglass, E. R., Stokes, P., \& Fiksenbaum, L. (2005). Engagement, work stress and wellbeing: Implications for psychological functioning. Stress News: The Journal of the International Stress Management Association, 17, 4-7.

Hisli, N. (1985). Beck Depresyon Envanterinin gecerliligi uzerine bir calisma. Psikoloji Dergisi, 6, 118-122.

Kim, H. K., \& McKenry, P. C. (2002). The relationship between marriage and psychological well-being: A Longitudinal analysis. Journal of Family Issues, 23, 885-911.

Lamb, K.A., Lee, G.R., \& DeMarris, A. (2003). Union formation and depression: Selection and relationship effects. Journal of Marriage and Family, 65, 953-962.

Lazarus, R. S. \& Folkman, S. (1984). Stress, appraisal and coping. Springer. New York.

Lazarus, R. S. (1993) Coping theory and research: Past, present, and future. Psychosomatic Medicine, 55, 234-247.

Oliver, J. M., \& Simmons, M. E. (1985). Affective disorders and depression as measured by the Diagnostic Interview Schedule and the Beck Depression Inventory in an unselected adult population. Journal of Clinical Psychology, 41, 469-477.

Pahkala, K., Kesti, E., Koengaes-Saviaro, P., Laippala, P. et al. (1995). Prevalence of depression in an aged population in Finland. Social Psychiatry and Psychiatric Epidemiology, 30, 99-106. 
Pasikowski, T., Sek, H., Greenglass, E. R., \& Taubert, S. (2002). The Proactive Coping Inventory-Polish Adaptation. Polish Psychological Bulletin, 33, 41-46.

Pierce, G. R., Sarason, I. G., \& Sarason, B. R. (1996). Coping and social support. In M. Zeidner \& N. S. Endler (Eds.), Handbook of coping: Theory, research, applications. (pp. 434-451): John Wiley \& Sons.

Rim, Y. (1990). Optimism and coping styles. Personality and Individual Differences, 11, 8990.

Ross, C. E., \& Van Willigen, M. (1997). Education and subjective quality of life. Journal of Health and Social Behaviour, 38, 275-297.

Ross, C. E., Mirowsky, J., Goldsteen, K. (1990). The impact of the family on health: The deacde in review. Journal of Marriage and the Family, 52, 1059-1078.

Scheier, M. F. \& Carver, S. C. (1985). Optimism, coping, and health: Assessment and implications of generalized outcome expectancies. Health Psychology, 4, 219-247.

Scheier, M. F., \& Carver, C. S. (1992). Effects of optimism on psychological and physical well-being: theoretical overview and empirical update. Cognitive Therapy and Research, 16, 201-228.

Scheier, M. F., Carver, C. S. \& Bridges, M. W. (1994). Distinguishing optimism from neuroticism (and trait anxiety, self-mastery, and self-esteem): A reevaluation of the Life Orientation Test. Journal of Personality and Social Psychology, 67, 10631078.

Scheier, M. F., Carver, C. S., \& Bridges, M. W. (2001). Optimism, pessimism, and psychological well-being. In E. C. Chang (Ed.), Optimism \& pessimism: Implications for theory, research, and practice. (pp. 189-216): American Psychological Association. 
Schwarzer, R. (1999a, July). Proactive coping theory. Paper presented at the $20^{\text {th }}$ International Conference of the Stress and Anxiety Research Society (STAR), Cracow, Poland.

Schwarzer, R. (2000). Manage stress at work through preventive and proactive coping. In E. A. Locke (ed.), The Blackwell handbook of principles of organizational behavior (pp. 342-355). Blackwell Publishers, Oxford, UK.

Seligman, M. E. P. (1990). Learned optimism. New York: Simon \& Schuster

Shehan, C. L. (1984). Wives' work and psychological well-being: An extension of Gove's social role theory of depression. Sex Roles, 11, 881-899.

Sheldon, K.M. \& King, L. (2001). Why positive psychology is necessary? American Psychologist, 56, 216-217.

Statistics Canada (2001). Available at: http://www12.statcan.ca/english/census01/home/index.cfm

Taylor, S. E. \& Aspinwall, L. G. (1996). Mediating and moderating processes in psychosocial stress: Appraisal. Coping, resistance, and vulnerability. In H. B. Kaplan (Ed.), Psychosocial stress: Perspectives on structure, theory, life-course, and methods (pp. 71-10). San Diego, CA: Academic Press.

Ying, Y. W. (1988). Depressive symptamotology among Chinese-Americans as measured by the CES-D. Journal of Clinical Psychology, 44, 739-746. 


\section{Footnotes}

${ }^{1}$ Analyses were repeated excluding the participants who were not born in Turkey. The results did not change, so we included them in the final analyses.

${ }^{2}$ In order to examine the low reliability score of the optimism scale, we conducted a factor analysis. The results of a principal component analysis, regardless of the type of rotation, suggested a two-factor solution. The emerging factors could not be interpreted in a meaningful way. Nevertheless, to examine if these two factors affected the analyses reported here, all analyses were conducted twice, with each factor separately. As no significant changes in the results were observed, the original optimism scores were used in all analyses. Also, deletion of no item increased the alpha. The low reliability of the scale may be an indication for potential differences in this immigrant group in terms of how optimism is viewed and experienced. This point calls for the attention of future research.

${ }^{3}$ Four filler items in the revised LOT were excluded for the purpose of shortening the length of the questionnaire.

${ }^{4}$ There was little variability in where participants were born -most participants reported Turkey as their birth place-, therefore birth place was not included in the regression analyses. Also, because age and years spent in Canada were highly correlated, we chose to include years in Canada only to avoid multicollinearity and also because this is a more relevant variable in a sample of immigrants. 